\title{
A spatially explicit ecosystem model of seston depletion in dense mussel culture
}

\author{
Jon Grant ${ }^{\mathrm{a},{ }^{*}}$, Cedric Bacher ${ }^{\mathrm{b}}$, Peter J. Cranford ${ }^{\mathrm{c}}$, Thomas Guyondet $^{\mathrm{d}}$ and Michel Carreau ${ }^{\mathrm{e}}$ \\ a Department of Oceanography, Dalhousie University, Halifax, Nova Scotia, Canada B3H 4J1 \\ ${ }^{\mathrm{b}}$ Institut Français de Recherche pour l'Exploitation de la Mer, BP 70, 29280 Plouzané, France \\ cedric.bacher@ifremer.fr \\ ${ }^{c}$ Ecosystem Research Division, Department of Fisheries and Oceans, Bedford Institute of Oceanography, \\ Dartmouth, Nova Scotia, Canada B2Y 4A2 crandfordp@mar.dfo-mpo.gc.ca \\ d Institut des Sciences de la Mer de Rimouski (ISMER), Université du Québec à Rimouski (UQAR), Rimouski, \\ Québec, Canada G5L 3A1 \\ e Synexus Global BU, Hatch Ltd., 5 Place Ville Marie Suite 200, Montréal, Québec, Canada H3B 2G2
}

*: Corresponding author : Jon Grant, Tel.: +1 902494 2021; fax: +1 902482 3410, email address : jon.grant@dal.ca

\begin{abstract}
:
A fully-coupled biological-physical-chemical model of a coastal ecosystem was constructed to examine the impact of suspended mussel culture on phytoplankton biomass in Tracadie Bay, Prince Edward Island, Canada. Due to the extent of mussel culture there, we hypothesised that shellfish filtration would control the concentration and distribution of phytoplankton and other suspended particles in the bay. Circulation was delineated with a tidally-driven 2D numerical model and used to drive an ecosystem model with a focus on pelagic components including phytoplankton production, nutrients, detritus, and mussels. The benthos were treated as a sink. Nutrients and seston were forced by tidal exchange and river input, with phytoplankton additionally forced by light. Boundary conditions of seston and nutrients were derived from field studies with an emphasis on the contrast between spring (high river nutrients, low temperature) and summer (low river inputs and high temperatures). Model output was used to map phytoplankton carbon over the bay for each season and in the presence of mussels and river nutrient input. Results indicate severe depletion effects of mussel culture on overall phytoplankton biomass, but no spatial pattern that can be attributed to grazing alone. Primary production generated by nutrient-rich river water created a mid-bay spike in phytoplankton that dominated the spatial pattern of chlorophyll-based carbon. Model results were validated with surveys from a towed sensor array (Acrobat) that confirmed the river influence and indicated bay-wide depletion of $29 \%$ between high and low water. Our model results indicate that the farm-scale depletion emphasised in previous studies cannot simply be extrapolated to seston limitation at the ecosystem level.
\end{abstract}

Keywords: Ecosystem model; Estuaries; Shellfish aquaculture; Carrying capacity; Phytoplankton; Circulation model; Nutrient dynamics; Towed sensors 


\section{Introduction}

Culture of shellfish is an important activity in many coastal zones worldwide. Prediction of appropriate culture density and location is essential in order to avoid exceeding carrying capacity of the environment to provide food resource for the animals and assimilate culture wastes. The former is particularly important for suspension-feeding bivalves which have a tremendous capacity to deplete the water column of particles via filtration. Food limitation may thus be the primary regulator of bivalve culture (Grant 1996). This concept originated with studies of natural bivalve populations, comparing estuarine volumes filtered to physical exchange of the tidal prism (Officer et al. 1982; Dame 1996). Wildish and Kristmanson (1996) applied this idea at the local scale using current speed to parameterise seston renewal. These results indicated that large bivalve populations could deplete particles much faster than flushing could renew them. Calculations of this type are applicable only in a bulk sense, without regard to spatial distribution. Estuaries contain strong gradients in flushing arising from proximity to river and inlet flow, as well as in bathymetry (Monsen et al. 2002). Hydrodynamics may therefore control the food supply to benthic organisms (Roegner 1998). A single box approach is often unsuitable for this degree of variation. Nonetheless, depletion indices are a valuable initial stage in the estimation of production carrying capacity as a basic scaling argument.

A second level of models with spatial detail has emerged with focus on culture management. Because tidal prism calculations are not applicable beyond a bulk exchange scale, a numerical model of circulation is required, and forms the basis of spatial models applied to bivalve culture (Grant and Bacher 2001). Finite element or finite difference models are frequently employed for this purpose, and represent a significant part of the effort involved in simulating the ecosystem. The spatial detail of these models and the need to define two- or three-dimensional water column structure, are important considerations for the configuration and implementation of corresponding ecosystem models.

The inclusion of spatially explicit circulation data is a precursor to models more complex than single boxes. A field campaign is required for circulation groundtruthing, consisting of at least sea level data and possibly current meter studies. Ranging from multiple boxes to mapped results, spatial models are an effective way to examine the effects of culture distribution. In these models, trophic interactions take place in each spatial unit or cell, and a hydrodynamic engine conducts the correct advection-diffusion between adjacent cells. Forced at boundaries such as a tidal inlet or river, the seston field is constantly evolving in response to grazing, exchange, sinking, and other processes. Although more spatial detail is usually desirable, the tradeoff of development time and computation requirements makes a spatially realistic model less common. Developments in GIS and computer mapping have facilitated further spatial realism.

A related class of coupled trophic models are the so-called PNZ (phytoplankton-nutrientszooplankton) models applied to oceanic environments (e.g. Newberger et al. 2003). Though conceptually similar to the PNZ models, culture models are different in that they integrate individual-based models of the cultured organisms, include spatially rigid farm sites and cultured biomass, often require benthic submodels due to shallow depth, and include suspended sediment as an important component. A variation on this approach applied to mussel culture is in Dowd (2005).

Fully coupled map-compliant models of bivalve culture are however relatively rare. Duarte et al. (2003) examined polyculture of kelp and scallops in a Chinese bay. Similarly, Pastres et al. (2001) used a coupled model to map the growth of Manila clam culture in Venice Lagoon. These models focused on bivalve growth as an output variable, since it is of obvious interest for cultured species, and is an integrative metric that is not subject to short-term variation. More dynamic variables such as seston concentration are less commonly modeled in detailed space since they require time scales of hours corresponding to forcing by tides, wind, grazing, etc. Due to this tight time-dependence, there is no equilibrium state, and results viewed as maps are only snapshots of constantly evolving seston fields.

Processes such as seston depletion have often been modeled locally because attenuation of particles through series of longlines or other suspended culture is an obvious length scale (Pilditch et al. 2001). These studies are important for smaller scale assessment of grazing effects, but are not intended to consider the trophic interactions of an entire ecosystem or interactions between multiple farms as occurs in dense culture. 
Despite the rather dramatic magnitude of bivalve-particle interactions suggested in the literature, it has been difficult to document these effects in the field. Depletion at single points has been shown in studies of benthic mussel beds (Frechette et al. 1989) or in water tunnel experiments over natural populations (Asmus et al. 1992). In any case, seston depletion may be a temporary phenomenon occurring on a time scale of hours, requiring intensive sampling (Strohmeier et a. 2005). Beyond single or closely spaced points, the time required for water sampling over a sizeable spatial scale is longer than the persistence of the effect, i.e. water column properties change faster than one is able to conduct a synoptic survey. Stations sampled later during the survey experience different tidal stages than those sampled initially, making a map-based analysis tenuous. Although instrument moorings have been used to get around this problem of temporal variability, they are usually spatially sparse and also unsuitable for mapping. An effective solution, employed in this study, is deployment of a towed vehicle with a GPS/sensor array which can map at a survey time scale suitable to estuarine variation.

Although simulation of the entire ecosystem is desirable, this approach is more suited to longer term simulations (e.g. annual) with time dependence in forcing. The short time scale of many hydrodynamic models and the detailed spatial grid less suited to simulations over annual cycles due to long computation times. We therefore focus on several processes likely to influence seston depletion including primary production, mussel grazing, and physical exchange over a period of about one month. This time scale has reasonable runtimes ( $<1$ day), and is long enough to achieve steady state relative to constant boundary conditions.

Based on observations of seston depletion at farm scales, we hypothesise that a bay with extensive areas of culture would display system-wide evidence of seston limitation. Several sub-hypotheses may be generated based on the extent of mussel culture and the physiography of the bay:

1. seston depletion by cultured mussels coupled with reduced tidal exchange inshore from the inlet lead to a declining gradient in phytoplankton biomass from the mouth to the head of the bay;

2. internal primary production fuelled by nutrients from rivers somewhat mitigates seston depletion due to suspension feeding.

In the present study, we employed a fully-coupled biophysical model to examine seston depletion in dense mussel culture in eastern Canada (Tracadie Bay, Prince Edward Island). This shallow bay contains multiple farm sites operating in a limited geographical area. In order to study seston depletion over estuarine scales, we undertook field and modelling studies of Tracadie Bay with the following objectives;

(a) construct a coupled biophysical ecosystem model of shellfish culture, (b) map depletion of phytoplankton as a function of bivalve grazing, (c) validate the model with spatially dense field measurements, (d) compare the relative magnitude of internal primary production, tidal exchange, and bivalve filtration in affecting seston concentration, (e) utilise model results to explain variation in growth due to food limitation of cultured mussels, and ( $f$ ) consider the farm management implications of seston depletion as an indicator of carrying capacity. 


\section{Materials and Methods}

\subsection{Study Site}

Modeling and field studies were conducted in Tracadie Bay, a shallow bar-built estuary on the north shore of Prince Edward Island, Canada. Longline mussel culture is conducted in most of the bay, at depths ranging from 3-6 m (Fig. 1). Winter Harbour, which empties into Tracadie Bay, and southern Tracadie Bay are used primarily for spat collection, while adult grow-out operations occur mainly in central and northern Tracadie Bay. Tides are mixed semidiurnal with a range of $\sim 60 \mathrm{~cm}$. A narrow inlet bounded by barrier islands restricts tidal flow, and the mouth of the bay contains a large tidal delta with extensive eelgrass beds. There is input of freshwater from the Winter River, which drains a $117 \mathrm{~km}^{2}$ watershed. However, river flow is low for much of the year $\left(\sim 1 \mathrm{~m}^{3} / \mathrm{s}\right)$ and outflow has only a small seasonal influence on the density structure of Tracadie Bay (Cranford, personal observation). Based on our knowledge of line spacing, areas under cultivation, and harvest, a reasonable estimate of mussel density averaged over the farmed areas is 20 individuals $\mathrm{m}^{-3}$ with approximately $50 \%$ being in their second year of culture. Owing to the small size of first-year mussels, and their relatively low food intake rate, only the density of second-year mussels is considered in model applications.

\subsection{Coupled Model}

The physical-biological model consists of a two-dimensional finite element circulation model (Aquadyn; www.technum.com) linked to biological components written in Matlab (www.mathworks.com) (Fig. 2). An existing Aquadyn model previously applied to Tracadie Bay (Grant et al. 2005) was updated to include more detail in the inlet region, and incorporate wind as well as tidal forcing. The finite element mesh contained 606 nodes, with boundaries and bathymetry digitised from a hydrographic chart (Fig. 2). The model was forced by a pure tide constructed from appropriate harmonics. Resulting current velocities were used in the transport scheme as specified below. In order to illustrate the gradient in flushing characteristic of Tracadie Bay, a tracer of 10 arbitrary units was introduced to the mouth every 30 minutes for 21 days using Aquadyn's transport scheme. A time of 21 days was selected as greater than the flushing time of the upper bay, but less than the flushing time of the inner bay, i.e. concentration gradients due to exchange are preserved.

Carbon-based submodels of primary production, detritus, and mussel bioenergetics were based on previous formulations applied to aquaculture sites including Tracadie Bay (Grant et al. 1993; Dowd 1997; Dowd 2005; Grant et al. 2005; Grant et al., accepted) originating with model structure and equations from Kremer and Nixon (1978). Because the model equations have been so extensively documented in our previous work, we provide here only a summary and overview of the model details.

Two-dimensional diffusion-advection of particulate and dissolved quantities was handled within AquaDyn via the following equation (Eq. 1):

(1)

$$
T=\frac{\partial C}{\partial t}+U \frac{\partial C}{\partial x}+V \frac{\partial C}{\partial y}-\frac{\partial}{\partial x}\left(D x \frac{\partial C}{\partial x}\right)-\frac{\partial}{\partial y}\left(D y \frac{\partial C}{\partial y}\right)
$$

where $\mathrm{C}=$ concentration of the quantity of interest, $\mathrm{U}$ and $\mathrm{V}$ are two horizontal components of depthaveraged velocity, and Dx and Dy are dispersion coefficients in directions $\mathrm{x}$ and $\mathrm{y}$.

Physics and biology are coupled via a Visual Basic connection in which the transport of phytoplankton, organic detritus, and dissolved nutrients are undertaken according to Eq. 1 and sent back to Matlab at each 0.5 hour time step for biological processing (e.g. photosynthesis). New results are then returned to AquaDyn at each time step. Due to the short duration of model runs, fixed boundary values for nutrients, detritus, and chlorophyll and water temperature were used, specific to the season in which the model was initialised (Table 1). The model was forced at the inlet mouth by tides and boundary conditions and run for 40 days at which equilibrium conditions were observed to occur. Nutrients from the Winter River provided the only internal forcing, with boundary concentrations given in Table 1 . Within the model domain, mussels are fixed at specific nodes corresponding to the mussel grow-out areas (Fig. 2). Model runs were 
first carried out with average spring and summer boundary values, determined using data from a multiyear sampling program, and next using values corresponding to June and August bay-wide seston mapping surveys (see below).

We used the coupled model to examine the influence on seston fields of mussel density and seasonal variation in temperature and nutrient input. The primary model result is the spatial distribution of chlorophyll in Tracadie Bay since it reflects the major part of mussel food, and can be groundtruthed with spatial data. The model produces output in the form of a map, where values at each node were smoothed using contours via kriging in Surfer (www.goldensoftware.com). Due to variation in transport over springneap conditions, node-specific values are variable, such that the map is also changing over time. We thus map equilibrium values (40 days) in order to represent modelled chlorophyll fields in the bay. Groundtruthing data from the BIO-Acrobat towed vehicle (see below) are in the form of chlorophyll concentrations along vertically-averaged transects. Model output at 40 days was sampled along a corresponding transect for comparison to survey data averaged over either ebb or flood tide.

\subsection{Ecological model}

The biological, particle, and nutrient components consist of submodels for mussels, phytoplankton, total nutrients (ammonia + nitrate), and detrital seston. No grazers are included except for mussels. Model units are in $\mathrm{mg} \mathrm{C} \mathrm{m}^{-3}$, except dissolved nutrients which are $\mathrm{mg} \mathrm{N} \mathrm{m}^{-3}$. Mussels consume two food sources, parameterised as phytoplankton carbon $(P$; calculated as [chl concentration*carbon/chl] where carbon/chl $=50)$, and detrital carbon seston $\left(S\right.$; calculated as particulate organic matter $(\mathrm{POM})^{\star} 0.5$ phytoplankton carbon).

\subsection{Mussels}

Mussels are modeled as individuals approximately 1 year in age, with initial dry weight $\left(M_{W}\right)$ of 250 $\mathrm{mg} \mathrm{C}$ ind $^{-1}$. Due to the short time scale of the model runs, we have used constants for some of the bioenergetic terms rather than functional relationships. Their growth rate is portrayed as scope for growth in the form of absorption minus respiration

$$
\frac{\partial M_{W}}{\partial t}=F\left(P * A E_{P}+S * A E_{s}\right)-R_{T}
$$

where clearance rate $F=2.4 \mathrm{I} \mathrm{h}^{-1}, \quad P$ and $S$ are phytoplankton and seston carbon concentration respectively, $A E_{P}$ is absorption efficiency for phytoplankton (0.9), and $A E_{S}$ is absorption efficiency for detrital seston (0.2). Respiration $\left(R_{T}\right)$ has a passive component $\left(0.01 \mathrm{~g} \mathrm{C}^{-1} \mathrm{ind}^{-1} \mathrm{~d}^{-1}\right)$ and an active component that is $10 \%$ of total absorption. Production of biodeposits is modeled as $I *(1-A E)$, where $I$ is ingestion rate $\left(F^{\star}(S+P)\right)$. All bioenergetic terms are adjusted allometrically for tissue weight change during simulations using exponents for respiration (0.6) and clearance (0.7). Population depletion of food particles is modeled as $F^{\star} P^{\star} M_{N}$ where $M_{N}$ is population density per $\mathrm{m}^{3}$.

\subsection{Phytoplankton}

Changes in the biomass of phytoplankton carbon $(P)$ were modeled as a balance between grazing, transport, and photosynthesis

$$
\frac{\partial P}{\partial t}=\gamma P-\lambda P-F P+T
$$

where $\gamma$ is a phytoplankton growth coefficient dependent on light, attenuation, nutrients, maximum rate of photosynthesis, and temperature as specified in Dowd (2005) and Grant et al. (accepted). $\lambda$ is a phytoplankton mortality coefficient (0.05) that includes sedimentation, but does not generate a specific sediment stock. Nutrients are limiting via a simple Michaelis-Menten function $\left(\mathrm{K}_{\mathrm{N}}=7 \mathrm{mg} \mathrm{m}^{-3}\right)$, and total dissolved inorganic nitrogen is the sole nutrient source arising from exchange at the oceanic boundary as well as inflow from Winter River. The light field is a function of latitude and day length, with a constant 
attenuation coefficient $\left(\mathrm{K}_{\mathrm{d}}=0.5\right) . F P$ is mussel ingestion of phytoplankton carbon $P$ as in Eq. 2 , and $T$ is advection according to Eq. 1.

\subsection{Other seston}

Seston $(S)$ in the form of organic carbon is subject to grazing, advection, and sinking:

$$
\frac{\partial S}{\partial t}=F S-\frac{W s}{z} S+T
$$

where $W_{S}$ is sinking rate $\left(0.5 \mathrm{~m} \mathrm{~d}^{-1}\right)$, and $z$ is water depth. Sedimentation is used as a sink in the model without interacting in other ecological processes. Although there is particulate carbon deposition, there is no mineralization included in the model.

\subsection{Nutrients}

Nutrients are modeled as nitrate + nitrite + ammonia, and are subject to exchange with the coastal ocean, input form Winter River, uptake by phytoplankton, and excretion by mussels:

$$
\frac{\partial N}{\partial t}=Q_{R} N_{R}+\lambda P(C / N)-M_{W} N_{M} R T(C / N)+T
$$

where $Q_{R}$ is river discharge with constant values for summer and spring $\left(1 \mathrm{~m}^{3} \mathrm{~s}^{-1}\right), N_{R}$ is nutrient content of river water estimated as a constant value in either summer or spring based on water sampling in Winter River (Table 2), and $\mathrm{C} / \mathrm{N}=7$ is carbon to nitrogen ratio of primary production and mussel tissue.

\subsection{Spatial data acquisition}

A computer-controlled undulating vehicle (Acrobat LTV-50, Sea Sciences, Inc. Arlington, Mass., USA) was used as a platform to carry environmental sensors for 3-D data acquisition surveys of the biophysical properties of the Tracadie Bay system. The Acrobat is lightweight and can be towed from the small boat $(5.2 \mathrm{~m})$ used in the study of this shallow embayment. The Acrobat flight path is controlled automatically during tows using computer inputs of vehicle position (GPS), water depth (transponder on boat) and vehicle depth (pressure sensor on Acrobat). The Acrobat sensor payload consisted of a CTD sensor (Applied Microsystems MicroCTD, Sidney, BC, Canada), a chlorophyll fluorometer (470 nm excitation and $685 \mathrm{~nm}$ emission set for 0.33 to $15 \mu \mathrm{g} \mathrm{l-1}$ range; Seapoint Sensors, Inc., Kingston, $\mathrm{NH}$, USA), a Mini-Optical Plankton Counter (Focal Technologies Corp., Dartmouth, NS, Canada), and a digital flowmeter (General Oceanics, Miami, FL, USA). During tows, water was drawn through the fluorometer by a submersible pump (Sea-Bird Electronics, Inc.) at a constant $100 \mathrm{ml} \mathrm{sec}-1$. This Acrobat system (BIOAcrobat) was powered from the surface by $12 \mathrm{~V}$ gel cell batteries and all measurements were made at a sampling frequency of $2 \mathrm{~Hz}$ (2 scans sec-1).

Owing to the extensive network of suspended longlines in Tracadie Bay, tows were generally confined to navigation channels. Data presented here are limited to a single transect in Tracadie Bay that ran largely in a north-south direction along the main axis of the embayment (Fig. 1). Data from the BIOAcrobat surveys, conducted at different tidal stages on June 17 (spring) and 18 and on August 21 (summer), were used to groundtruth model estimates of phytoplankton distribution in Tracadie Bay (Table 1). During each survey, the BIO-Acrobat was programmed to undulate between $0.5 \mathrm{~m}$ below the surface to $1 \mathrm{~m}$ above the seabed and was towed at $2 \mathrm{~m} \mathrm{~s}^{-1}$. Each survey was completed within 23-34 min. In vivo chlorophyll a fluorescence measurements from the BIO-Acrobat were calibrated against extracted chlorophyll a concentrations $\left(r^{2}=0.907 ; \mathrm{n}=57\right)$. Average chlorophyll concentrations were determined within the 1 to $3 \mathrm{~m}$ depth zone of each of 12 equidistant intervals along the Acrobat transect (0.2' latitude intervals [350 m] starting at $46^{\circ} 21.8^{\prime} \mathrm{N}$ latitude). Water less than $1 \mathrm{~m}$ depth is above the mussel long lines and the $>3 \mathrm{~m}$ depth interval tends to have elevated particle concentrations as a result of particle resuspension/settling processes in the near-seabed region. 


\section{Results}

\subsection{Hydrodynamic simulation of flushing}

We have previously provided details of circulation in Tracadie Bay (Grant et al. 2005), and only a summary relevant to the present model will be included here. A map of conservative tracer concentration after 21 days shows a strong gradient of exchange from outer to inner bay (Fig. 3). The inlet region has strong currents through its entrance and the outer region is well flushed in keeping with its renewal time of 8-9 days (Grant et al. 2005). Beyond the upper wide region of the bay, exchange is much slower. Flushing is reduced by one-half where the bay narrows, while Winter Harbour and the upper bay have an exchange rate of $\sim 20 \%$ compared to the inlet regions. The Winter River, and upper reaches of salt marsh regions off Winter Harbour are virtually stagnant with respect to tidal flushing.

\subsection{Observed bay-scale distribution of chlorophyll}

Although tidal circulation has a major effect on particle distribution (Fig. 2), this influence is highly dependent on the stage of the tidal cycle as indicated by the distribution of phytoplankton carbon (chlorophyll concentration $\times 50$ ) along the north-south axis of Tracadie Bay (Fig. 3). Both the June and August BIO-Acrobat surveys showed a similar pattern, with (a) a steady increase in chlorophyll from outer bay to a mid-bay peak which then tapers in the upper bay, and (b) increased chlorophyll at low tide compared to high tide. The pattern in (a) likely reflects exchange of bay waters from offshore, and translation of renewed phytoplankton into the bay. In terms of boundary forcing, chlorophyll values collected at a station located just outside the mouth of Tracadie Bay in the Gulf of St. Lawrence were 18 times higher during the August survey $\left(6.50 \mathrm{mg} \mathrm{chl} \mathrm{m}^{-3}\right)$ than was measured in June $\left(0.36 \mathrm{mg} \mathrm{chl} \mathrm{m}^{-3}\right)$ (Table 1). Despite the import of this phytoplankton carbon on flood tide, high tide phytoplankton biomass was not greatly different in August compared to June (Fig. 3).

The increased chlorophyll from low to high tides reflects river influence. Relatively high chlorophyll levels detected in the upper half of Winter Harbour at high tide (data not shown)) are exported to Tracadie Bay during late ebb tide, resulting in elevated chlorophyll values in the central part of the bay at low tide (Fig. 3). The June and August surveys were conducted under spring and neap tidal conditions, respectively (Table 2). The relatively high water volume exiting Winter Harbour on the June spring ebb tide enriched chlorophyll levels in Tracadie Bay to a greater degree than was observed under neap tide conditions in August (Fig. 3). As there was little difference in biomass in Winter River waters between spring and summer, we attribute this enhancement to greater tidal exchange in spring.

Prior to the emergence of this slug of river-borne chlorophyll, there is evidence of mussel grazing impact on pigment levels. The ebb tide transect survey conducted on June 17, 2003 is notable for the relatively low chlorophyll levels detected during this stage of the tidal cycle (Fig. 3A). This survey was conducted $3.75 \mathrm{~h}$ after high tide, during which time chlorophyll declined by as much as $35 \%$ in the central part of the Bay compared with high tide concentrations in the same geographic zone (Fig. 3; Zone 6). There was an average 29\% decrease in chlorophyll over this $3.75 \mathrm{~h}$ period across all zones surveyed along the full length of the Tracadie Bay transect (Fig. 3). The horizontal and vertical distribution of chlorophyll in the Bay over the tidal cycle indicates that this chlorophyll was not exported on the ebb tide and did not settle out of suspension, but appears to have been rapidly consumed within the Bay.

\subsection{Predicted phytoplankton distribution maps}

We used the model to first examine seasonal differences in chlorophyll as a function of mussel density, using boundary conditions for nutrients in Table 2. The default grazer-free case of spring river nutrient conditions reflects the balance between primary production and advection (Fig. 4). In spring conditions there is intense primary production in Winter Harbour arising from increased nutrient input into the river (Fig. 4A). This biomass declines rapidly along the length of Winter Harbour as nutrient are sequestered by ambient phytoplankton. Although there is a plume of higher biomass escaping the harbour, it is not apparent as an overall increase in biomass baywide. The outer region of the bay instead reflects low phytoplankton biomass conditions at the inlet boundary. 
The scenario of cultured mussel grazing under spring conditions $\left(10\right.$ mussels $\left.\mathrm{m}^{-3}\right)$ also features high primary production in Winter Harbour (grow-out culture is absent there), but there is a dramatic seston depletion effect in most of the bay, reducing chlorophyll-based carbon to less than half of the mussel-free condition (Fig. 4B). The dispersion of phytoplankton-enriched water exiting Winter Harbour is reduced in the presence of grazers. The most depleted areas of the bay $\left(<50 \mathrm{mg} \mathrm{C} \mathrm{m}^{-3}\right)$ are the northeast corner with large areas of culture and its gyre circulation that limits seston renewal, and the uppermost part of the bay which has limited grow-out, but receives little tidal exchange of previously filtered water.

The grazer-free case of typical summer river nutrient conditions indicates that local production arising from nutrients in Winter Harbour, as well as in the outer bay, maintain phytoplankton carbon at $>60 \mathrm{mg} \mathrm{C} \mathrm{m}^{-3}$ throughout the bay (Fig. $5 \mathrm{~A}$ ). Tidal exchange with carbon-poor coastal water causes a lower standing stock near the inlet but nitrogen is renewed at this boundary as well, and internal primary production increases through the entrance region. Some of the highest biomass in Tracadie Bay is predicted in the northern shoreline behind the barrier beach in an area with a gyre that optimises tidal renewal of nutrients, and accumulation of internal production.

Proceeding landward from the inlet there is an ever-decreasing level of phytoplankton biomass as primary production becomes nutrient limited. The biomass of Winter Harbour phytoplankton in summer (Fig. 5A) is considerably lower than predicted for the spring (Fig. 4A), owing to lower nutrient levels in river water under summer conditions (Table 2). Winter Harbour seems to have little influence on this declining trend of biomass along the main axis of the bay.

The addition of mussels at commercial densities has a dramatic effect on the summer phytoplankton distribution (Fig. 5B). The major portion of the bay experiences biomass at low levels which are, in most cases less than the baywide minimum concentrations in the absence of grazing. Winter Harbour also displays reduced biomass because, although there is no local grazing, water entering this part of the system has been filtered by culture in the larger bay. The region near the inlet has increased biomass because there is no local culture there, and it benefits from tidal exchange. It is apparent that herbivory not only impacts the main bay, but also affects the coupling of the Winter River with the rest of the estuary. Upper Tracadie Bay displays limited exchange but substantial grazer demand from cultured mussels, and exhibits severe phytoplankton depletion.

\subsection{Model and data comparisons}

In order to make appropriate comparisons between Acrobat observations and model simulations, the model was run using the nutrient boundary conditions measured at the time of the spring and summer Acrobat surveys (Table 2). Mapped outputs from these simulations indicate that in both seasons there is high biomass of phytoplankton in Winter Harbour owing to the similarly high $\mathrm{N}$ content measured in the river (Table 2, Fig. 6). In the absence of grazers, the high river nutrients observed during Acrobat spring conditions allow Winter River primary production to spread throughout the bay (Fig. 6A). The transect sampled from this scenario is an important end member in the model-observation comparisons below.

Even in the presence of mussel grazers, there are important seasonal differences with higher carbon levels in the outer bay during August compared to June. This result is driven by tidal import where boundary conditions for phytoplankton are an order of magnitude greater than in spring (Table 2, Fig. 6A, B). Although the Acrobat transects we examine below are somewhat removed horizontally from the outflow of Winter Harbour, the central region of the bay is influenced by the export of phytoplankton from the Harbour and should be detectable in the transect (Fig. 6).

In order to facilitate a quantitative comparison of model predictions with Acrobat measurements, spatial model output for the different scenarios (Fig. 6) was subsampled at grid nodes located along the Acrobat survey transect. We consider only June because there is more tidal information in the spring Acrobat survey, and because June and August mapped predictions show similar results. Model predictions in the presence $\left(10 \mathrm{~m}^{-3}\right)$ and absence of mussels are temporally averaged over the tidal cycle and the illustrated range in predicted biomass is induced by temporal variation in tides (Fig. 7). With the 
addition of mussels, spring biomass is predicted to be greatly reduced from $\sim 200 \mathrm{mg} \mathrm{C} \mathrm{m}^{3}$ to under 60 $\mathrm{mg} \mathrm{C} \mathrm{m}{ }^{3}$.

The BIO-Acrobat surveys in June reflect conditions during specific tidal phases so some care is required when comparing these data to the temporally averaged, steady state model predictions. Phytoplankton in the central Bay at low tide is elevated by the export of chlorophyll from upper Winter Harbour during late ebb tide (Fig. 7). Since this biomass has less exposure to mussel grazing in Tracadie Bay, it corresponds to chlorophyll-carbon distributions in the Bay under the 'no mussels' scenario. Their patterns are similar with a mid-bay peak in biomass forced by the river, and a northward decline toward the inlet. The predicted versus observed curves are dispalced in concentration since the Acrobat data invariably has some influence of mussel grazing.

As indicated in Fig. 3, the data obtained during high tide represents conditions where the low tide biomass is reduced by both dilution with water entering from the Gulf (low phytoplankton levels, Table 2) and by mussel grazing (Fig. 7). The ebb tide survey, which was conducted prior to the export of new chlorophyll from upper Winter Harbour, represents the tidal stage when the water in Tracadie Bay has been exposed to mussels the longest and therefore has the highest potential for particle depletion. The model transect in the presence of mussel grazing matches closely with Acrobat observations under tidal conditions expected to reflect seston depletion due to suspension feeding.

\section{Discussion}

Our study is unique because it provides detailed mapped model results of seston distribution in the presence of bivalve herbivory, and includes ecosystem processes beyond the area of single farming sites. Moreover, we were able to incorporate a detailed circulation model to examine seston variation interacting over multiple farms in a large culture area. Other system-level features such as river/nutrient influence on primary production have also been included with this approach. We were thus able to investigate the fate of phytoplankton subjected to top-down regulation via grazing as well as physical controls on standing stocks and and bottom up regulation of primary production.

The control of phytoplankton biomass is central to our modeling study. While grazing is an obvious control on the standing stock of primary producers, nutrient levels and flushing are important forcing terms in the model, as verified in the literature (Roegner and Shanks 2001; Jassby et al. 2002). Rather than use the model to explore primary production, we have sought to produce a reasonable simulation of phytoplankton biomass in order to include internal production as a source term in the flux of mussel food. Because primary production responds to the input of river nutrients, a forcing of known importance in this bay, we were able to isolate this single variable as contributing to mussel food. This is by no means a comprehensive examination of nutrient cycling as is underway in our subsequent work.

The ability of natural and cultured bivalve populations to deplete coastal waters of seston has been recognised as a common attribute of these ecosystems. This grazer regulation is so significant as to control the spring bloom in some estuaries (Cloern 1982). The scaling between tidal renewal of particles and their depletion by filtration has been formalised in indices proposed by Dame (1996) and Wildish and Kristmanson (1996). These relationships form the basis for our modeling efforts. Despite the importance of top-down regulation of estuarine primary production, there are relatively few studies that attempt to measure or model these processes. Although there are ecosystem models which incorporate grazing by natural bivalve populations (Gerritsen et al. 1994), these modeling efforts have been more extnesively applied to aquacultured populations. The models, including our own previous work, are similar to the present study in utilizing fully coupled simulations of primary production, bivalve bioenergetics, and advection-diffusion (Duarte et al. 2003; Nunes et al. 2003; Pastres et al. 2001). A critical difference however, is that the previous models have focused on integrated bivalve growth, often with daily or longer time scales. Our focus on seston depletion is based on a shorter time scale (hours) to resolve particle dynamics in a way that is less feasible with growth models using annual cycles.

Many studies of suspension feeders concentrate on local depletion (farm scale) with respect to particle transport, filtration rate and culture density. Verhagen (1982) and Campbell et al. (1998) combine vertical dispersion, local advection and mussel ecophysiology model to simulate growth of mussels 
reared on the bottom. Incze et al. (1981) and Karayücel and Karayücel (1998) computed horizontal depletion within longlines to yield simple indicators of acceptable density of cultured animals. Pouvreau et al. (2000) and Bacher et al. (2003) coupled a depletion equation to a growth model to assess the relationship between individual growth and density of cultivated animals at the scale of longlines. Pilditch et al. (2001) constructed one of the most detailed physical models to date using two-dimensional flow to generate local maps of seston depletion within a farm, the only example of mapped seston depletion prior to our work. In local models, the spatial scale is within-farm, usually over 10-100 m length scales, and in all cases, models examine a balance between shellfish biomass, feeding, current speed, and farm size. For example, Ibarra (2003) modeled chlorophyll depletion through mussel longlines and estimated that $33 \%$ of ambient chlorophyll was reduced over $350 \mathrm{~m}$.

Efforts to groundthruth these models are largely based on the use of one or more fluorometers or other instruments placed within the farm, or on the collection of multiple water samples. Although groundtruthing is sometimes sparse, Strohmeier et al. (2005) measured chlorophyll depletion (water sampling approach) and current speed reduction to calculate that food availability was reduced up to $80 \%$ in the first $30 \mathrm{~m}$ of a longline mussel farm. These models neglect primary production or other source-sink terms since the time scale of minutes to hours obviates their inclusion. Flow and bathymetry are either constant or greatly simplified due to the small spatial scale. Although these models provide an important means to evaluate farm-scale depletion and thus modification of farm design, they are applicable only locally, and suffer from limited groundtruthing.

In the literature, there is a tendency to relate seston depletion to growth anecdotally, with arbitrary values chosen for acceptable levels of depletion. Our previous studies of mussel growth in Tracadie Bay provide some calibration of this relationship. Mussels were grown in cages for 2 years at locations including both ends of the Acrobat transect (Waite et al. 2005). This study shows a halving of autumn tissue weight from outer to inner sites, over the distance that model results (summer; no river nutrients) predicted a $67 \%$ reduction in chlorophyll (Fig. 6). Similar predictions were made for growth rate vs. seston depletion in Grant (1999). In Pouvreau et al's (2000) model, a doubling of seston depletion causes a drop in tissue weight of pearl oysters of $20-50 \%$. There is an obvious compromise between stocking density and growth rate (Raillard and Menesguen 1994).

Our model is intentionally simplified with respect to trophic structure and time dependence, especially in the boundary conditions and mussel bioenergetics. We have chosen this approach to isolate the spatial extent of mussel culture and its effect on seston fields as a primary focus. The short time scale inherent in seston depletion facilitated the use of constant values for many variables. Detailed mapping of seston dynamics within Tracadie Bay indicates that seston depletion is highly location-dependent. We emphasise that this is a very different result than the growth rate maps produced in other fully coupled models (see above). Because seston depletion is a direct measure of food availability, it allows bay-scale planning of culture siting to avoid potential depletion zones or to arrange culture to avoid a depletion bottleneck that will affect multiple farms downstream. Conversely, culture planning could take advantage of high seston regions such as the mouth of Winter Harbour.

Coupling of the ecological model to an Aquadyn hydrodynamic model proved an effective approach to generating a biophysical model. Matlab provided ready communication with Aquadyn via Visual Basic, a link that can be utilised with Aquadyn models of other ecosystems using the same Matlab model code. In addition, the grid structure in Aquadyn provides the spatial structure for the ecosystem model including the location of culture farms. As a 2D model, this approach is more suited to well-mixed estuaries, such as Tracadie Bay. Mapped model results can assume an important role in coastal management since they are amenable to inclusion in GIS with other types of environmental and resource data.

We emphasise several important observations about the shape and magnitude of both model and field results. First, we expected a directional decrease in phytoplankton from north to south as tidal water is progressively filtered by mussel farms (see Dowd 2005). The mapped results for summer conditions in the presence of mussel indicate this trend. However, the importance of Winter Harbour in supplying internal production to central Tracadie Bay is evident in the mapped simulations for Acrobat summer conditions, despite high chlorophyll carbon at the inlet boundary. Model transects highlight a mid-transect maximum caused by the influence of seston emerging from Winter Harbour. Export from Winter River is apparent in low tide Acrobat data as well as model output. These results suggest that despite the 
influence of mussels on particle budgets, their effect on spatial distribution of seston is not overriding. This is not to say that they do not have an important influence on seston; model and field results indicate that mussels control the overall level of phytoplankton in the bay under both spring and summer conditions.

The BIO-Acrobat chlorophyll data indicate an interplay of mussel grazing vs. tidal and river input and its subsequent dilution. They also show the importance of Winter Harbour internal production as a food source to the culture of mussels in Tracadie Bay. The high productivity results from nutrient enhancement to Winter River by runoff from a watershed that supports an agricultural landscape consisting primarily of potato farms. The BIO-Acrobat data also provides insight into the time-scale of seston depletion. Over a $3.75 \mathrm{~h}$ period immediately after high tide when there are no important external (Gulf of St. Lawrence and Winter Harbour) sources of phytoplankton to Tracadie Bay, phytoplankton levels along the Acrobat transect in June declined by an average of $28 \%$.

Beyond the modeling components, we incorporate via the BIO-Acrobat a unique means to spatially groundtruth model results, a significant limitation in previous studies. Even for an estuary the size of Tracadie Bay, water sampling or instrument profiling is too time consuming to eliminate the temporal variability that will confound spatial data obtained over several hours. The BIO-Acrobat sampling approach achieves far greater spatial resolution over these areas in a time-frame that is able to account for tidal cycle variations in seston distribution.

The equilibrium model maps that we have shown model do not capture the extent of tidal variation in the field data. Nonetheless, a mean curve derived from the individual tidal series shows remarkable similarity to the model curve for a fixed mussel density. We conclude that the model is able to embody the essential components controlling phytoplankton in the bay, despite the relatively simple ecosystem structure that we employ. In addition, while farm-scale models are instructive at the local level, they do not always have direct implications for processes operating at larger scales. For this reason, ecosystemscale models are necessary to understand the relationship between multiple farms and the implication for carrying capacity of entire bays.

\section{Acknowledgements}

This research was funded by the Natural Sciences and Engineering Research Council of Canada (NSERC).

\section{References}

Bacher, C., Grant, J., Hawkins, A., Fang, J., Zhu, P., Duarte, P., 2003. Modeling the effect of food depletion on scallop growth in Sungo Bay (China). Aquat. Living Resour., 16: 10-24.

Campbell, D.E., Newell, C.R., 1998. MUSMOD, a production model for bottom culture of the blue mussel, Mytilus edulis L. J. Exp. Mar. Biol. Ecol., 219: 171-203.

Cloern J.E., 1982. Does the benthos control phytoplankton biomass in south San Francisco Bay (USA)?. Mar. Ecol. Prog. Ser., 9: 191-202.

Dame, R.F., 1996. Ecology of bivalves: an ecosystem approach. CRC Press LLC, Boca Raton.

Dowd, M., 1997. On predicting the growth of cultured bivalves. Ecol. Model., 104: 113-131.

Dowd, M., 2005. A bio-physical coastal ecosystem model for assessing environmental effects of marine bivalve aquaculture. Ecol. Model., 183: 323-346.

Duarte, P., Menese, R., Hawkins, A.J.S., Zhu, M., Fang, J., Grant, J., 2003. Mathematical modeling to assess the carrying capacity for multi-species culture within coastal waters. Ecol. Model., 168: 109143.

Fréchette M./Butman C. A. and W. R. Geyer. 1989. The importance of boundary layer flows in supplying phytoplankton to the suspension feeder, Mytilus edulis L. Limnol. Oceanogr. 34: 19-36.

Gerritsen, J., Holland, A.F., Irvine, D.E., 1994. Suspension-feeding bivalves and the fate of primary production: An estuarine model applied to Chesapeake Bay. Estuaries, 17: 403-416. 
Grant J. 1996. The relationship of bioenergtics and the environment to the field growth of cultured bivalves. J. Exp. Mar. Biol. Ecol. 200: 239-56.

Grant, J.,1999. Preliminary models of seston depletion and growth variation in cultured mussels. Bull. Aquacult. Assoc. Canada, 99-2: 5-8.

Grant J, Dowd M, Thompson K, Emerson C, Hatcher A. Perspectives on field studies and related biological models of bivalve growth. In: Bivalve filter feeders and marine ecosystem processes . 371-420. 1993. New York, Springer Verlag.

Grant, J., Bacher, C., 2001. A numerical model of flow modification induced by suspended aquaculture in a Chinese bay. Can. J. Fish. Aquat. Sci., 58: 1003-1011.

Grant, J., Curran, K.J., Guyondet, T.L., Tita, G., Bacher, C., Koutitonsky, V., accepted. A box model of carrying capacity for suspended mussel aquaculture in Lagune de la Grande-Entrée, Iles-de-la-Madeleine, Québec. Ecol. Model.

Grant, J., Cranford, P., Carreau, M., Schofield, B., Armsworthy, S., Burdett-Coutts, V., Ibarra, D., 2005. A model of aquaculture impacts for multiple estuaries and its field verification at mussel culture sites in Eastern Canada. Can. J. Fish. Aquat. Sci., 62: 1271-1285.

Incze, L., Lutz, R.A., True, E., 1981. Modeling carrying capacities for bivalve molluscs in open, suspended-culture systems. J. World Maricult. Soc., 12: 143-55.

Jassby, A.D., Cloern, J.E., Cole, B. E., 2002. Annual primary production: Patterns and mechanisms of change in a nutrient-rich tidal ecosystem. Limnol. Oceanogr., 47: 698-712.

Karayücel, S., Karayücel, I., 1998. Estimating the carrying capacity of mussel raft systems in two Scottish sea lochs. Isr. J. Aquacult.- Bamidgeh, 50: 12-19.

Monsen, N.E., Cloern, J.E., Lucas, L.V., Monismith, S.G., 2002. A comment on the use of flushing time, residence time, and age as transport time scales. Limnol. Oceanogr., 47: 1545-1553.

Newberger, P.A., Allen, J.S., Spitz, Y.H., 2003. Analysis and comparison of three ecosystem models. J. Geophys. Res. (C Oceans), 108 C3: 3061.

Nunes, J.P., Ferrerira, J.G., Gazeau, F., Lencart-Silva, J., Zhang, X.L., Zhu, M.Y., Fang, J.G., 2003. A model for sustainable management shellfish polyculture in coastal bays. Aquaculture, 219: 257-277.

Officer, C.B., Smayda, T.J., Mann, R., 1982. Benthic filter feeding: a natural eutrophication control. Mar. Ecol. Prog. Ser., 9: 203-10.

Pastres, R., Solidoro, C., Cossarini, G., Canu, D.M., Dejak, C., 2001. Managing the rearing of Tapes philippinarum in the lagoon of Venice: a decision support system. Ecol. Model., 138: 231-245.

Pilditch, C.A., Grant, J., Bryan, K.R., 2001. Seston supply to sea scallops (Placopecten magellanicus) in suspended culture. Can. J. Fish. Aquat. Sci., 58: 241-53.

Pilditch C. A., J. Grant, K. R. Bryan. 2001. Seston supply to sea scallops (Placopecten magellanicus) in suspended culture. Can. J. Fish. Aquat. Sci. 58: 241-53.

Pouvreau, S., Bacher, C., Heral, M., 2000. Ecophysiological model of growth and reproduction of the black pearl oyster, Pinctada margaritifera: potential applications for pearl farming in French Polynesia. Aquaculture, 186: 117-144.

Raillard, O. Menesguen, A., 1994. An ecosystem box model for estimating the carrying capacity of a macrotidal shellfish system. Mar. Ecol. Prog. Ser., 115:117-130.

Roegner, G.C., 1998. Hydrodynamic control of supply of suspended chlorophyll a to infaunal estuarine bivalves. Estuar. Coast. Shelf Sci., 47: 369-384.

Roegner, G. C., Shanks, A.L., 2001. Import of coastally-derived chlorophyll a to South Slough, Oregon. Estuaries, 24: 244-256

Strohmeier, T., Aure, J., Duinker, A., Castberg, T., Svardai, A., Strand, O., 2005. Flow reduction, seston depletion, meat content and distribution of diarrhetic shellfish toxins in a long-line blue mussel (Mytilus edulis) farm. J. Shellfish Res., 24: 15-24.

Verhagen, J.H.G., 1982. A distribution and population model of the mussel Mytilus edulis in lake Grevelingen. $3^{\text {rd }}$ International Conference on State-of-the-art in Ecological Modeling, Colorado State University, May 24-28. Denver, Colorado, pp. 373-383.

Waite, L., Grant, J., Davidson, J., 2005. Bay-scale spatial growth variation of mussels Mytilus edulis in suspended culture, Prince Edward Island, Canada. Mar. Ecol. Prog. Ser., 297: 157-67.

Wildish, D., Kristmanson, D., 1996. Benthic suspension feeders and flow. Cambridge University Press, New York. 


\section{Table 1.}

Details of BIO-Acrobat surveys of Tracadie Bay. Survey elevation designated depth below (-) or above (+) mean low tide.

$\begin{array}{lcccc}\text { Date } & \begin{array}{c}\text { Start Time } \\ \text { (GMT) }\end{array} & \begin{array}{c}\text { Survey Tidal } \\ \text { Elevation }(\mathrm{cm})\end{array} & \begin{array}{c}\text { Daily Tidal } \\ \text { Range }(\mathrm{cm})\end{array} & \begin{array}{c}\text { Temperature } \\ \text { Range }\end{array} \\ \text { 17 June, 2003 } & 1615 & -1 \text { (ebb tide) } & -41-59 & 10.4-15.6 \\ \text { 17 June, 2003 } & 2227 & -37 \text { (low tide) } & -41-59 & 10.2-16.5 \\ \text { 18 June, 2003 } & 1250 & 52 \text { (high tide) } & -36-54 & 10.1-15.2 \\ \text { 20 August, 2003 } & 1459 & -12 \text { (low tide) } & -15-25 & 22.9-23.3 \\ \text { 21 August, 2003 } & 0300 & 27 \text { (high tide) } & -16-29 & 22.7-24.3\end{array}$

Table 2.

Boundary condition values used to force the model under typical spring and summer conditions (Seasonal) and corresponding to conditions observed during the Acrobat surveys in June and August 2003 (Groundtruthing).

\begin{tabular}{|c|c|c|c|c|c|c|c|c|}
\hline \multirow{3}{*}{ Parameter } & \multicolumn{4}{|c|}{ Seasonal } & \multicolumn{4}{|c|}{ Groundtruthing } \\
\hline & \multicolumn{2}{|c|}{ Spring } & \multicolumn{2}{|c|}{ Summer } & \multicolumn{2}{|c|}{ June 6-21, 2003} & \multicolumn{2}{|c|}{ Aug. 18-21, 2003} \\
\hline & River & Outside & River & Outside & River & Outside & River & Outside \\
\hline $\begin{array}{l}\text { Chlorophyll } \\
\left(\mathrm{mg} \mathrm{C}^{3} \mathrm{~m}^{3}\right)\end{array}$ & $0^{a}$ & 50 & $0^{\mathrm{a}}$ & 50 & $0^{a}$ & 18 & $0^{a}$ & 325 \\
\hline $\begin{array}{l}\text { Total N } \\
\left(\mathrm{mg} \mathrm{N} / \mathrm{m}^{3}\right)\end{array}$ & 840 & 30 & 50 & 30 & 1651 & 16.9 & 1703 & 13.4 \\
\hline
\end{tabular}


Figure 1. A. Map of Tracadie Bay including A. location map in Eastern Canada, B. location of culture sites in the bay, and $\mathrm{C}$. bathymetry and Acrobat towed vehicle sampling transects.

Figure 2. A. Finite element grid of Tracadie Bay used in the hydrodynamic model and in spatial configuration of the ecological model. B. Distribution after 21 days of a conservative tracer continuously introduced through the inlet
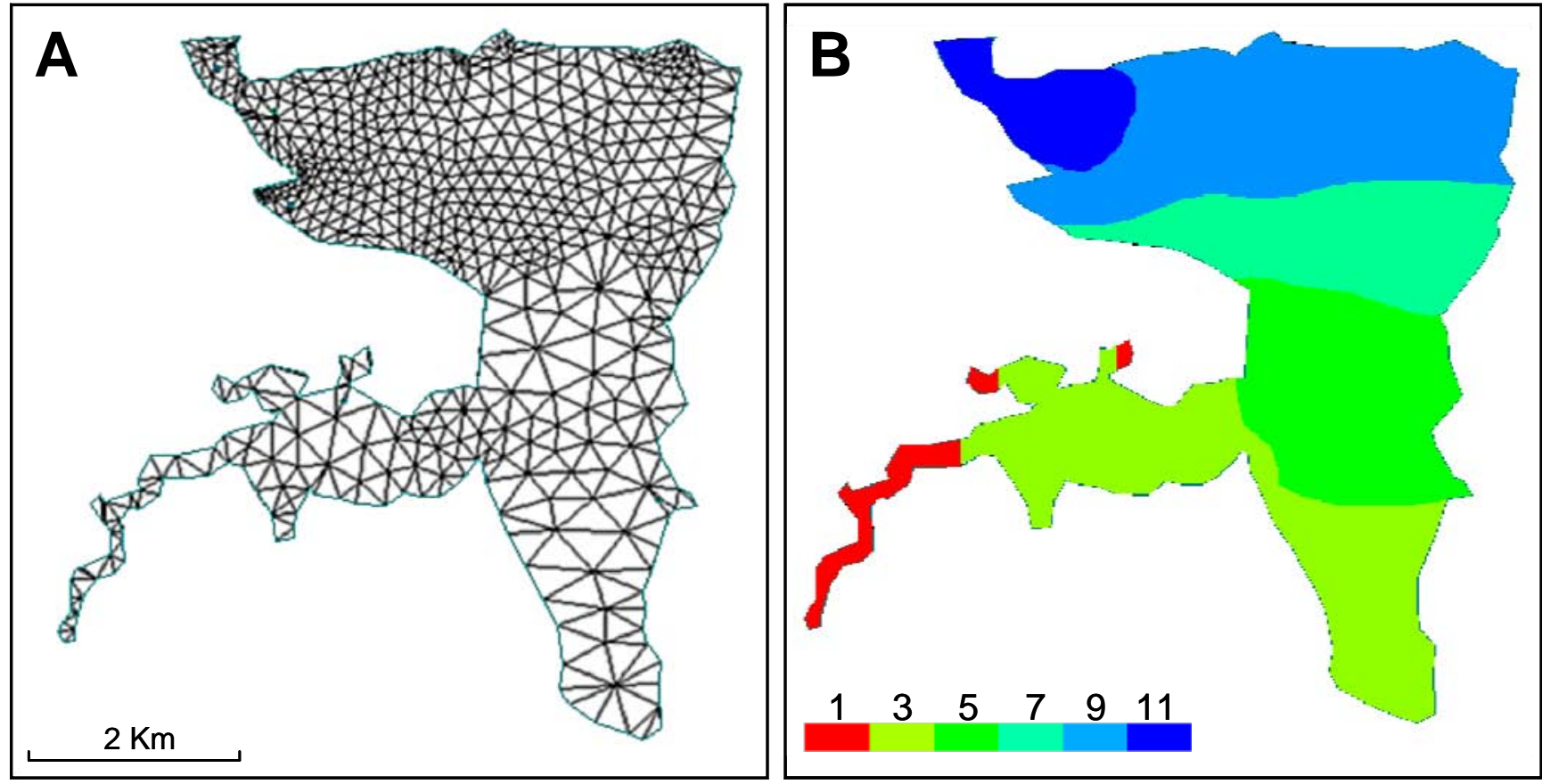
Figure 3. Average phytoplankton carbon concentrations in the 1-3 $\mathrm{m}$ depth zone along the north-south transect in Tracadie Bay (Fig. 1) during BIO-Acrobat surveys in A. June and B. August 2003. Survey parameters are specified in Table 1.

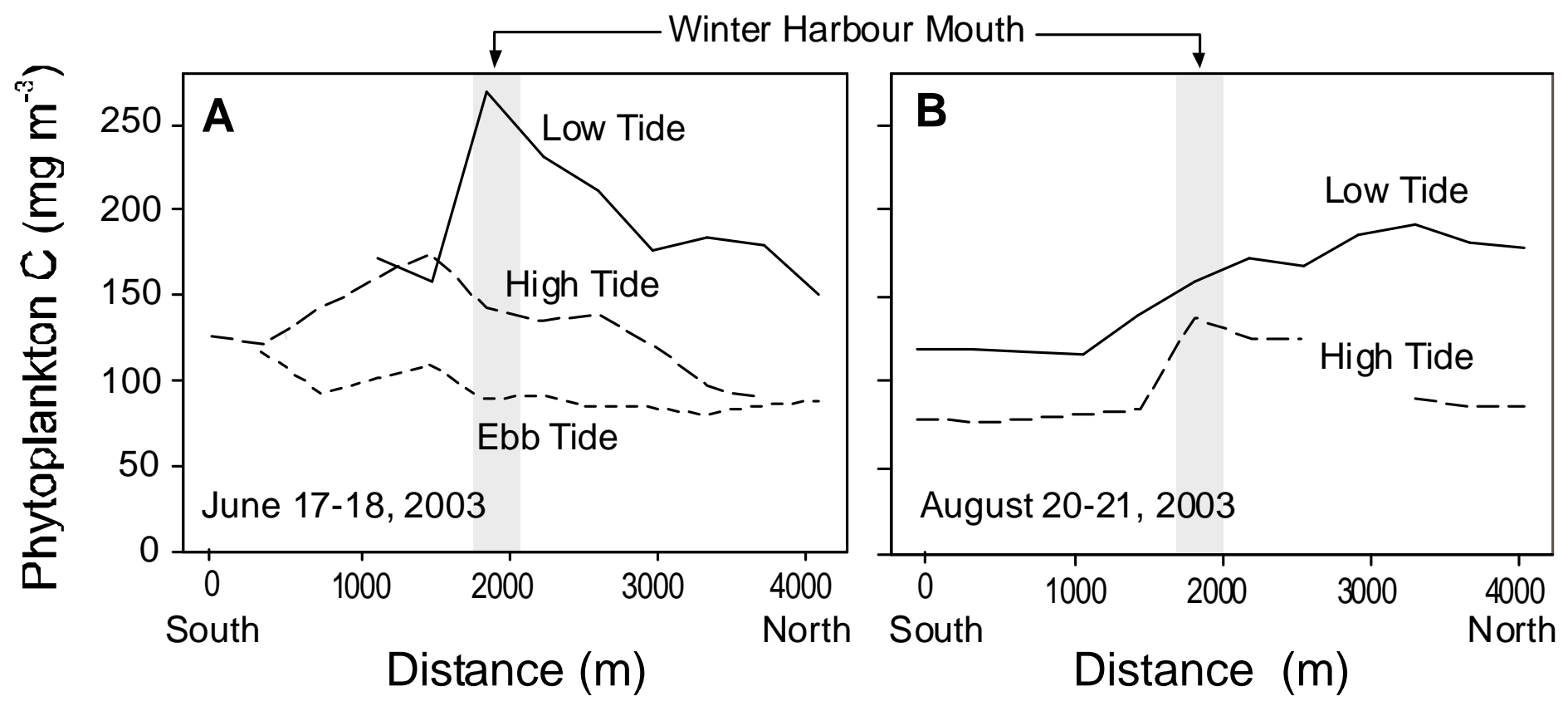


Figure 4. Map of chlorophyll-based carbon distribution in Tracadie Bay for spring conditions of $\mathrm{A}$. zero mussels and B. 10 mussels $\mathrm{m}^{-2}$ with mussel farm locations given on Fig. 1. Boundary conditions of these simulations are specified in Table 2.
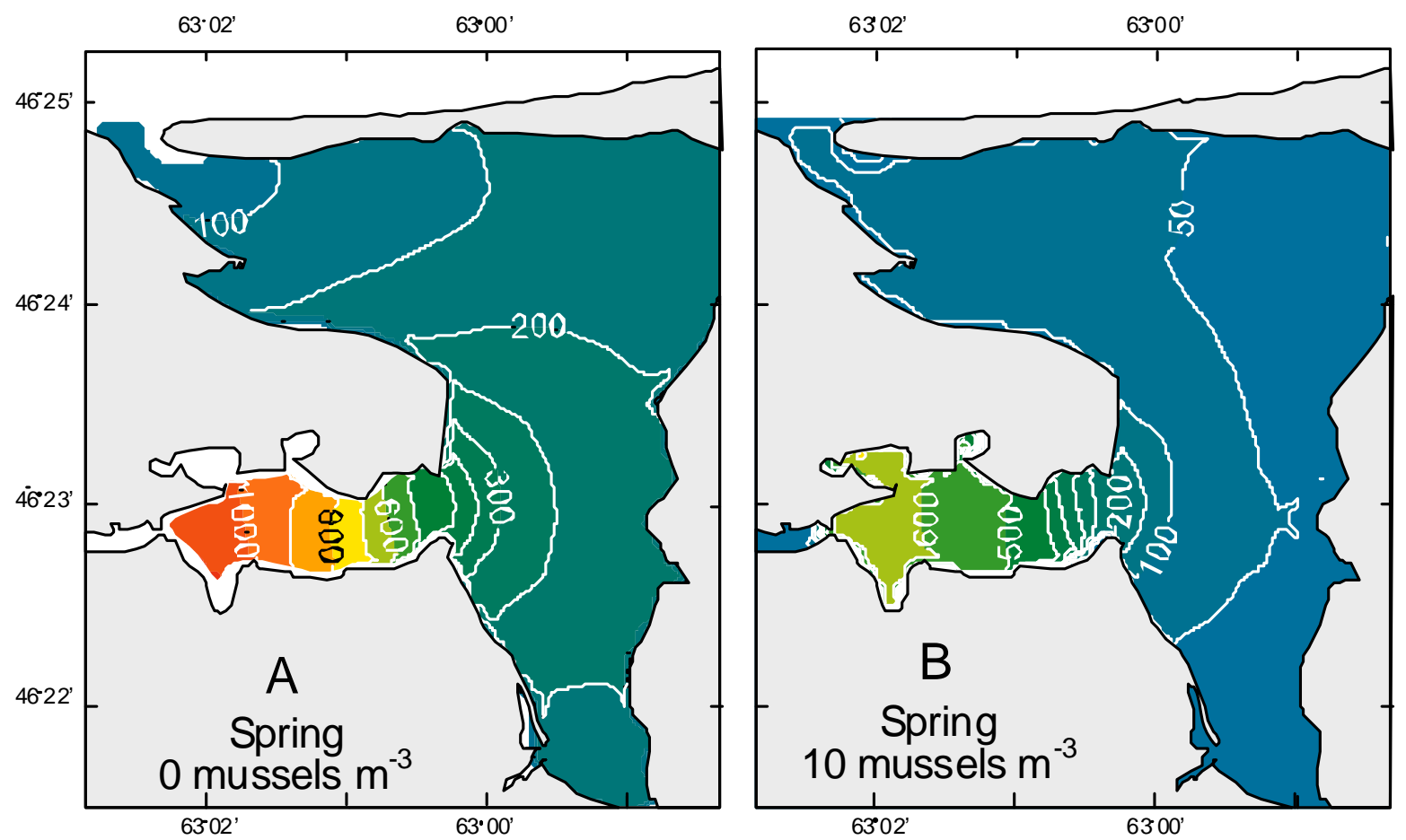

$\mathrm{mg} \mathrm{C} \mathrm{m}^{-3}$

1200

1000

800

600

400

300

200

100

0 
Figure 5. Map of chlorophyll-based carbon distribution in Tracadie Bay for summer conditions of A. zero mussels and B. 10 mussels $\mathrm{m}^{-2}$ with mussel farm locations given on Fig. 1. Boundary conditions of these simulations are specified in Table 2.
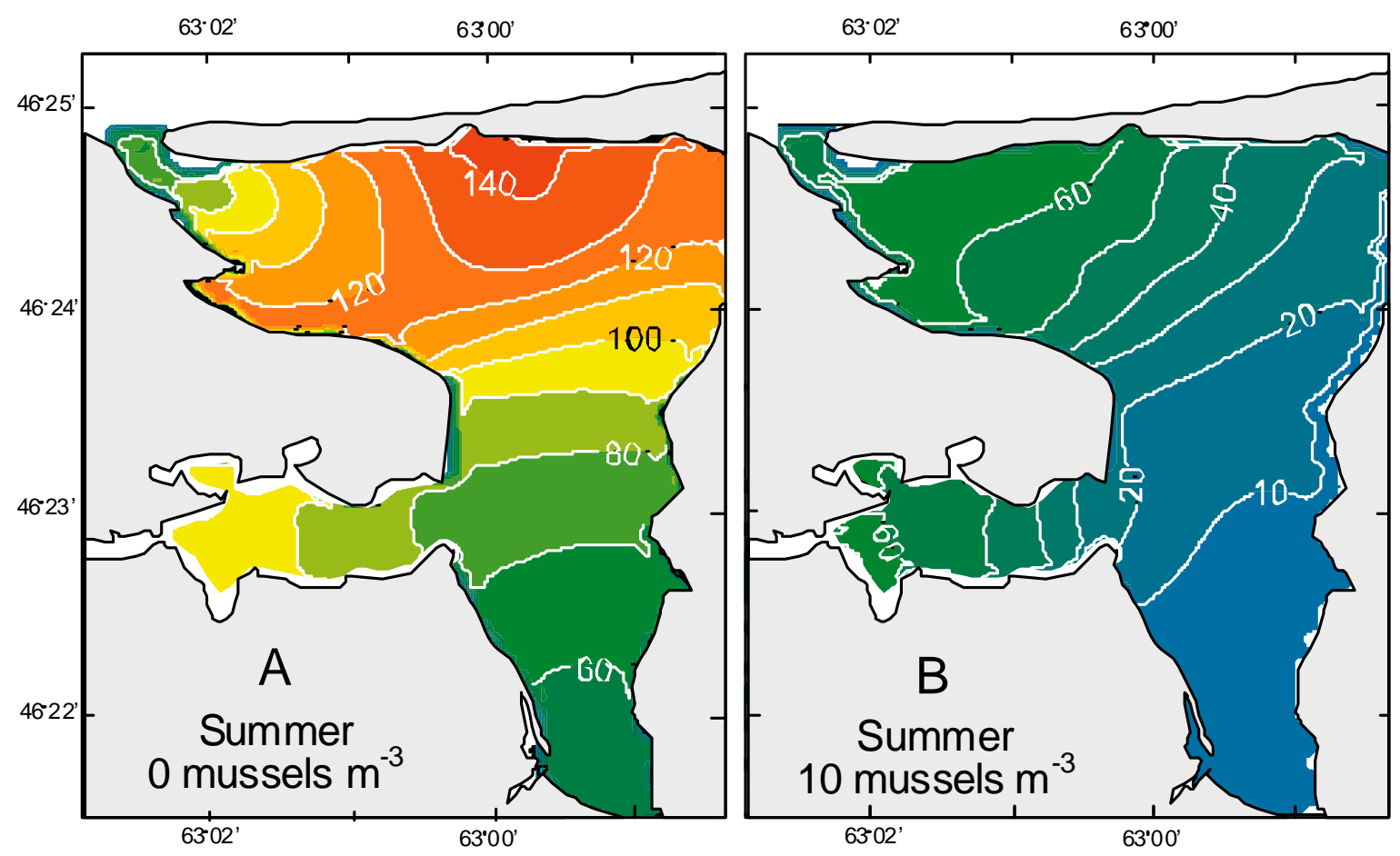

$\mathrm{mg} \mathrm{C} \mathrm{m}^{-3}$

160

140

120

100

80

60

40

20

0 
Figure 6. Maps of chlorophyll-based carbon distribution in Tracadie Bay estimated using boundary conditions measured during the Acribat surveys in A. June (no mussels), B. June (mussel density of $10 \mathrm{~m}^{-3}$ ) and August (mussel density of $10 \mathrm{~m}^{-3}$ ) 2003. The location of the Acrobat sampling transect is shown (yellow lines). Model boundary condition data are provided in Table 2.
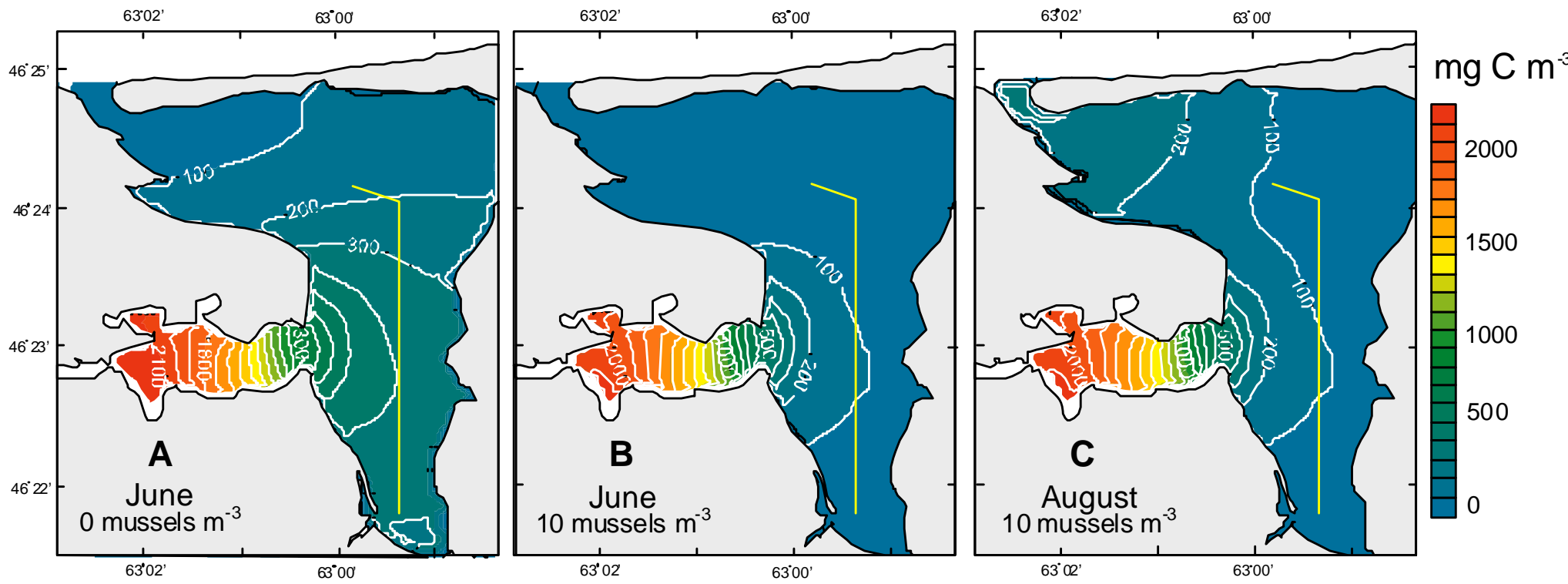
Figure 7. Comparison of Acrobat (lines) and model (shaded areas) estimates of phytoplankton carbon concentration along a linearised transect running from south to north Tracadie Bay (Fig. 1). Acrobat data were collected at the indicated tidal stages on June 17 and 18, 2003 and were averaged over a 1 to $3 \mathrm{~m}$ depth range within each $350 \mathrm{~m}$ interval along the transect. Boundary conditions specific to the Acrobat surveys (Table 2) were used in the model simulations as indicated.

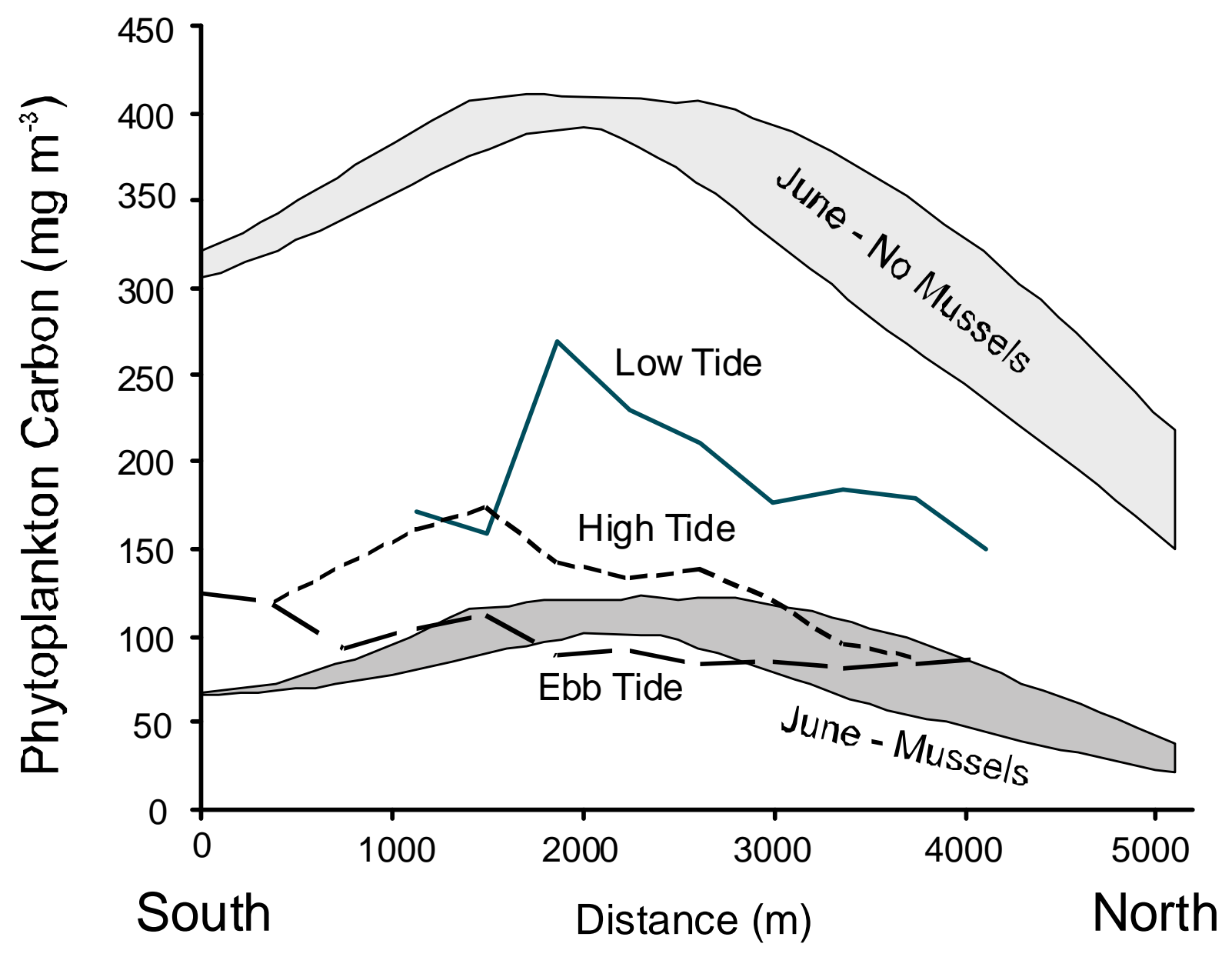

